\title{
Skin pathology of the elderly patients: Case of black African
}

\section{Almamy Diabaté1, Hamdan Sarah Kourouma², Bamba Vagamon', Irené Gué1, Mamadou Kaloga ${ }^{2}$, Boussou Romain Aka ${ }^{1}$}

\author{
${ }^{1}$ Dermatology Department, University Teaching Hospital, Bouaké, Côte d'Ivoire, ${ }^{2}$ Dermatology Department, University \\ Teaching Hospital of Treichville, Abidjan, Côte d'Ivoire
}

Corresponding author: Dr. Almamy Diabaté, E-mail: docalmamy@yahoo.fr

\begin{abstract}
Background: Skin diseases of the elderly subjects have clinical signs which are different from those of the young people. The purpose of this study was to determine the skin diseases that led elderly people to consult at the Department of Dermatology at the University Teaching Hospital in Bouaké, Côte d'Ivoire. Methods: That was a descriptive crosssectional study conducting between January 1,2015 and December 31, 2015 and including patients 65 years and older who were diagnosed with skin diseases the Department of Dermatology at the University Teaching Hospital in Bouaké, Côte d'Ivoire. Results: During the study period, 109 patients aged 65 years and older (1.8\%) were recruited. These patients consulted for 227 diagnoses. The average age of the patients was 71.8 and sex ratio was 0.7. Mycoses were the major reason for consultation (18.7\%) followed by pruritus (17.9\%), eczema (13.1\%), and (9.0\%) tumors with $76.5 \%$ of benign tumors and (5.1\%) disorders of keratinization. Leg ulcers were 2.1\%. Mycoses were represented by intertrigo $(52.9 \%)$ and dermatomycosis of the glabrous skin (25.7\%). Kaposi sarcoma and keloid were the most frequent tumors. Conclusion: Our study shows a predominance of mycosis, eczema, and pruritus in the elderly subjects. Mycoses and pruritus could result from the weather and the skin aging, respectively.
\end{abstract}

Key words: Cutaneous pathology; Elderly; Bouaké

\section{INTRODUCTION}

Skin pathologies of the elderly subjects are varied and display diagnosis, management, and follow-up issues [1]. Their symptomatology differs from that of the young subjects [2]. Several studies have been done in many countries to determine the profile of these disorders in the elderly [3-6]; however, the skin diseases of aged patients were undocumented in Côte d'Ivoire. The purpose of this study was to describe the features of cutaneous pathology in the elderly patients at the Department of Dermatology in Bouaké, Côte d'Ivoire.

\section{PATIENTS AND METHODS}

A transversal and multicenter study was conducted between January 2014 and December 2015 at the Department of Dermatology of the University Teaching Hospital in Bouaké. This study included patients 65 years and older who presented dermatologic conditions. Dermatologists collected the data based on age, sex, duration of evolution of the cutaneous pathology before the consultation and the new diagnoses of each patient. Patients gave the written consent. All data were analysed by Epi Info 3.5.1.

\section{RESULTS}

During the study period, 109 (1.8\%) out of 6055 patients who consulted for 227 diagnoses and were aged 65 years and over. The mean age of the patients were $71.8 \pm 6.5$ years old with extremes: $65-95$ years. The peak age was between 65 and 74 years with $68.7 \%$. Among 109 patients, 46 were male and 63 were female with a sex ratio of 0.7 . The female predominance was found in all age groups. The Table 1 summarizes the cutaneous pathologies. Mycoses were the most frequent infectious skin diseases and all skin diseases, affecting

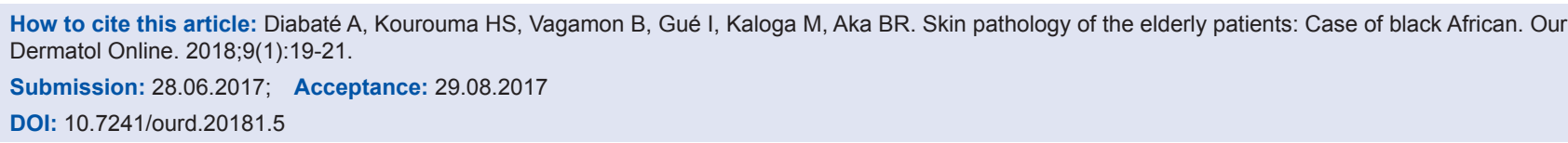


more female than male. The intertrigos (41.7\%) were predominant followed by the onychomycoses (31.4\%), and the dermatomycoses of the glabrous skin (15.7\%). Bacterial skin diseases were prevalent in female (sex ratio:1.7) and represented by pyodermitis (75\%) and erysipelas (25\%). The most common viral dermatosis was shingles $(68.8 \%)$ which was $2.9 \%$ of all skin diseases. 12 cases of parasitic skin diseases were scabies. Senile pruritus (36 cases) associated cutaneous xerosis (14) was found. The isolated skin xerosis was identified in 6 cases. The eczema and the urticaria were diagnosed in 19 cases and in 6 cases, respectively. Our study reported 23 cases of tumors: the benign tumors were keloid (32.7\%), cyst (23.1\%), and mollusca pendulum (8.5\%) and the malignant tumor was Kaposi sarcoma (1.9\%), melanoma $(0,8 \%)$, and squamous cell carcinoma $(0,4 \%)$. Palmoplantar keratodermia $(25 \%)$ was the most common keratinization disorder while vitiligo (75\%) was frequent in pigmentary disorders. Out of 8 cases of toxidermia, 7 cases were fixed pigmented erythema and 1 case of toxic epidermal necrolysis. Leg ulcers were predominant in male and occurred since 5 years. The connectivities were represented by 2 cases of discoid lupus and 1 case of scleroderma. 4 cases of autoimmune bullous dermatoses were consisted bullous pemphigoid ( 3 cases) and vulgar pemphigus (lcase).

Table 1: Dermatoses reported in our series

\begin{tabular}{lc} 
& Number of cases (\%) \\
\hline Infectious dermatoses & $79(34.8)$ \\
Fungal dermatoses & $48(21.1)$ \\
Bacterial dermatoses & $17(7.5)$ \\
Viral dermatoses & $8(3.5)$ \\
Parasitic dermatoses & $6(2.6)$ \\
Pruritus & $36(15.9)$ \\
Tumors & $23(10.1)$ \\
Benign tumors & $17(7.5)$ \\
Malignant tumors & $6(2.6)$ \\
Palmoplantar hyperkeratosis & $25(11)$ \\
Eczema & $19(8.4)$ \\
Cutaneous xerosis & $14(6.1)$ \\
Leg ulcer & $8(3.5)$ \\
Toxidermia & $8(3.5)$ \\
Urticaria & $6(2.6)$ \\
Autoimmune bullous Dermatoses & $4(1.8)$ \\
Connectivity & $3(1.3)$ \\
Total & $227(100)$ \\
\hline
\end{tabular}

\section{DISCUSSION}

In this study, the major reasons for consultation of the elderly were chronic pathological conditions. The small sample size of our population was the limitation of study. Therefore, we cannot extrapolate our results to all seniors in the city of Bouake and in the country. The issues of affordability of people in care could explain the small number of patients admitted at the hospital during the study period.

Interestingly, because of socio-economic, cultural, and health context and mildness of some skin diseases, people would undergo traditional treatments or selfmedication. Despite these limitations, this study has documented the main reasons of consultations of the elderly. In our study, the proportion of the elderly was lower than that reported in Tunisia $[3,4]$ and in Taiwan [5]. These results can be explained by the relative short life expectancy related to poverty and deficient health systems in Subsaharan Africa. In Ivory Coast, the rate of the elderly people was $3.9 \%$ of the population in 2014. Pitché et al. have identified significant difference between skin disorders in the elderly individuals and those in the general population. They revealed that mycosis, eczema, and pruritus were frequent in while eczema, mycosis, and the acne were the most occurring in the general population [7].

The high frequency of pruritus in the elderly is related to their age, their skin aging, and the xerosis. However, acne is a skin disease occurring in adolescents, and thus, representing the third reason of consultation in the youth who predominates in the general population.

Mycosis followed by eczema was the most common reason of consultation in the elderly in Tunisia as in our study $[3,4]$ compared with the Western countries where eczema followed by tumors were the most prevalent (Table 2). The climatic factors such as heat and humidity could be explain the high rate of mycoses in Africa.

The low value of malignant tumors in our study is discordant with several studies [3-5,8-10]. This

Table 2: Common dermatoses of the elderly in our series

\begin{tabular}{lccccc}
\hline & Our study Bouaké & Tunisia Sfax [4] & Croatia Karlovac [8] & Canada Ottawa [9] & USA New York [10] \\
\hline Mycosis (\%) & 21.1 & 16 & 6.81 & 3.4 & 4.5 \\
Eczema (\%) & 8.4 & 12 & 7.30 & 16.3 & 37.9 \\
Pruritus (\%) & 15.9 & 4.2 & 6.20 & 1.2 & 1.8 \\
BT $^{*}(\%)$ & 7.5 & 14.7 & 18.98 & 13.8 & 11.5 \\
MT** $\left.^{*} \%\right)$ & 2.6 & 12.3 & 9.37 & 12.6 & 9.0 \\
\hline
\end{tabular}

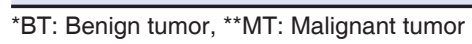


difference is due to genetically pigmented skin of our patients whose dense epidermal melanin protects them from ultraviolet radiation [11], and therefore, preventing them from skin cancers. In the present study, Kaposi sarcoma was the most common cancer which is similar to that of several Subsaharian African studies [12,13] and different from that of developed country studies in which basal cell carcinoma was the most prevalent [3-5].

This unusual frequency of the Kaposi sarcoma results from the increase of HIV prevalence in Africa [14]. Among benign tumors, keloids were predominant in our study compared to other studies where cysts or seborrheic keratoses were frequent [3].

\section{CONCLUSION}

This study shows a small proportion of the elderly subjects 65 years and older at the Dermatology Department in Bouaké. Cutaneous mycoses are the most common skin diseases in these patients in Africa. The most occurring mycoses could be due to the heat and the humidity.

\section{REFERENCES}

1. Farage MA, Miller KW, Berardesca E, Maibach HI. Clinical implications of aging skin: cutaneous disorders in the elderly. Am J Clin Dermatol. 2009;10:73-86.

2. Jafferany M, Huynh TV, Silverman MA, Zaidi Z. Geriatric dermatoses: a clinical review of skin diseases in an aging population. Int J Dermatol. 2012;51:509-2.

3. Souissi A, Zeglaoui F, El Fekih N, Fazaa B, Zouari B, Kamoun MR. Pathologie cutanée chez le sujet âgé: Etude multicentrique tunisienne. Ann Dermatol Venereol. 2006;133:231-4.

4. Mseddi M, Borgi N, Sellami L, Meziou TJ, Turki H, Zahaf A. Pathologie cutanée du sujet âgé en dermatologie. Ann Dermatol Venereol. 2006;133:272-4.

5. Liao YH, Chen KH, Tseng MP, Sun CC. Pattern of skin diseases in a geriatric patient group in Taiwan: a 7-year survey from the outpatient clinic of a university medical center. Dermatology. 2001;203:308-13.

6. Yalçin B, Tamer E, Toy GG, Oztas P, Hayran M, Alli N. The prevalence of skin diseases in the elderly: analysis of 4099 geriatric patients. Int J Dermatol. 2006;45:672-6.

7. Pitché P, Tchamdja S, Amanga Y, Tchangaï-Walla K. Pathologies dermatologiques en consultation hospitalière à Lomé (Togo). Nouv Dermatol. 1997;16:369-73.

8. Cvitanovic H, Knezevic E, Kuljanac I, Jancic E. Skin disease in a geriatric patients group in outpatient dermatologic clinic Karlovac, Croatia. Coll Antropol. 2010;34(Suppl 2):247-51.

9. Adam JE. The prevalence of skin disorders in geriatric age group. Australas J Dermatol. 1987;28:72-6.

10. Young AW. Dermatologic complaint presented by 330 geriatric patients. Geriatrics. 1958;13:428-34.

11. Alam M, Ratner D. Cutaneous squamous cell carcinoma. N Engl J Med. 2001;344:975-83.

12. Asuquo ME, Ebughe G. Cutaneous cancers in Calabar, Southern Nigeria. Dermatol Online J. 2009;15:11.

13. Saka B, Souley Z, Kombaté K, Mouhari-Toure A, Akakpo S, Napo-Koura G, et al. Les cancers cutanés au Togo: étude de 223 observations. Med Trop. 2010;70:169-71.

14. ONUSIDA. Genève: ONUSIDA; 2010. Rapport sur l'épidémie mondiale de VIH/sida, 2010; p. 364.

Copyright by Almamy Diabaté, et al. This is an open-access article distributed under the terms of the Creative Commons Attribution License, which permits unrestricted use, distribution, and reproduction in any medium, provided the original author and source are credited. Source of Support: Nil, Conflict of Interest: None declared. 